\title{
DISCUSSION
}

\section{Predicting tunnelling-induced ground movements and interpreting field measurements using numerical analysis: Crossrail case study at Hyde Park}

\author{
VASILEIOS AVGERINOS*, DAVID M. POTTS $\dagger$, JAMIE R. STANDING $\dagger$, MICHAEL S. P. WAN†, \\ EVANGELIA S. IERONYMAKI§, KATERINA BOUKIN $\|$ and ANDREW J. WHITTLE
}

\section{Contribution by Evangelia S. Ieronymaki, Katerina Boukin and Andrew J. Whittle}

The discussion contributors have read with great interest the authors' paper on numerical analyses for predicting the ground response to Crossrail tunnelling at two selected monitoring sections ( $\mathrm{X}$ and $\mathrm{Y}$ ) in Hyde Park (Avgerinos et al., 2018), and three other interrelated publications (Wan, 2014; Wan et al., 2017a, 2017b). The discussers have also used their own numerical method to interpret the reported measured surface and subsurface data and have found some differences with the authors' results that are worth mentioning. They also noticed some inconsistencies in the reported measured data among the four publications that deserve further clarification.

The authors fit conventional Gaussian curves to the measured surface settlements in order to estimate volume loss due to WB tunnel construction $\left(\Delta V_{\mathrm{L}} / V_{0}=0.78 \%\right.$ at section $\mathrm{X}$ and $0 \cdot 44 \%$ at section $\mathrm{Y}$ ). This volume loss for section $\mathrm{X}$ is then applied as a boundary condition in the two-dimensional (2D) finite-element analyses of ground deformations. According to the authors, conditions at section $\mathrm{X}$ are 'judged to be more representative of the 'greenfield' situation, being located further away from the Central Line tunnels'. The discussers have analysed measured data from nine instrumented sections in Hyde Park affected by the Crossrail construction (Ieronymaki, 2015; Ieronymaki et al., 2016), and noticed that the ground response is affected significantly by tunnel-boring machine (TBM) operational parameters. Their records indicate that TBM1 (WB tunnel) applied similar face pressure while passing under sections $\mathrm{X}$ and $\mathrm{Y}$, but lower grout pressure under section $\mathrm{X}$. This can be an additional reason for computing larger volume loss at that section.

The authors also report three different sets of measured surface settlements at section Y (Fig. 6.13 in Wan (2014), Figs 8(b) and 11(b) in Wan et al. (2017a) and Fig. 8(a) in Avgerinos et al. (2018)), as well as different measured subsurface settlements (in Wan (2014) compared with those

\footnotetext{
* Formerly Imperial College, London; now Geotechnical Consulting Group, London, UK (Orcid:0000-0001-5725-6857).

$\uparrow$ Department of Civil and Environmental Engineering, Imperial College, London, UK.

+ Formerly Imperial College, London; now Geotechnical Consulting Group, London, UK.

$\S$ Department of Civil and Environmental Engineering, Manhattan College, Riverdale, NY, USA (Orcid:0000-0003-3059-3639).

$\|$ Department of Civil and Environmental Engineering, Massachusetts Institute of Technology, Cambridge, MA, USA.

I Department of Civil and Environmental Engineering, Massachusetts Institute of Technology, Cambridge, MA, USA (Orcid:0000-0001-5358-4140).
}

reported in Wan et al. (2017b)). It appears that these differences arise due to refinements in datum selection and it would be helpful if the authors could clarify their rationale for adjustments in the reported measurements.

The discussers used their own numerical method (described in Ieronymaki et al. (2018)) to interpret the reported measured data at section Y after passage of the WB tunnel. Their method considers three modes of displacements around the tunnel cavity (uniform convergence $u_{\varepsilon}$, distortion $u_{\delta}$ and vertical translation $\Delta u_{v}$, as proposed by Whittle \& Sagaseta (2003), Pinto \& Whittle (2014) and Pinto et al. (2014)) and searches to obtain the optimum (minimum least-squares average error (LAE)) set of cavity deformation parameters in order to match measured surface and subsurface displacements.

This method was used to interpret ground movements for the same Crossrail contract (C300) in Hyde Park (section F; Ieronymaki et al., 2016). The discussers performed undrained analyses, using two soil models, the simple Mohr-Coulomb (with dilation) and the non-linear elastoplastic MIT-S1, calibrated against laboratory data for London Clay. Their results showed that both models fit very well the surface and subsurface measured data with negligible differences in the optimum set of cavity shape modes and volume losses. It has to be noted that the volume loss computed with these prior numerical analysis are similar to those obtained using a Gaussian fit to the surface settlements for both $\mathrm{WB}$ and $\mathrm{EB}$ tunnels (e.g. $\Delta V_{\mathrm{L}} / V_{0}=0.79 \%$ for $\mathrm{WB}$ numerical analyses with Mohr-Coulomb as opposed to $\Delta V_{\mathrm{L}} / V_{0}=0.74 \%$ for the Gaussian fit).

For section Y, they used a similar approach but limited their analysis to the Mohr-Coulomb soil model. Figs 22 and 23 show the comparison of their numerical analyses with the measured data for the WB surface and subsurface ground response, respectively, as reported both in Wan (2014) and Wan et al. (2017a). The numerical solutions fit very well the measured data with a small LAE of $0 \cdot 12 \mathrm{~mm}$ (using $n=220$ deformation component measurements) and volume losses, $\Delta V_{\mathrm{L}} / V_{0}=1 \cdot 01-1 \cdot 07 \%$.

The results achieve an excellent match to the measured data (with the exception of HP6 close to the springline of the tunnel) and confirm the importance of the cavity deformation components $\left(u_{\delta}\right.$ and $\left.\Delta u_{y}\right)$ that are not included in the analyses presented by the authors. The optimised cavity deformation parameters are very similar to those found previously at section $\mathrm{F}$ (section $\mathrm{F}: u_{\varepsilon}=-14 \mathrm{~mm}, u_{\delta}=4 \mathrm{~mm}$, $\Delta u_{y}=-7 \mathrm{~mm} ;$ section $\mathrm{Y}: u_{\varepsilon}=-18 \mathrm{~mm}, u_{\delta}=4 \mathrm{~mm}$, $\left.\Delta u_{y}=-4 \mathrm{~mm}\right)$. The results are expected given the similarities of the sections, while the higher volume loss can be attributed to the smaller earth pressure balance machine grout pressure applied while passing beneath section Y, given that the face pressures were similar for both sections. 


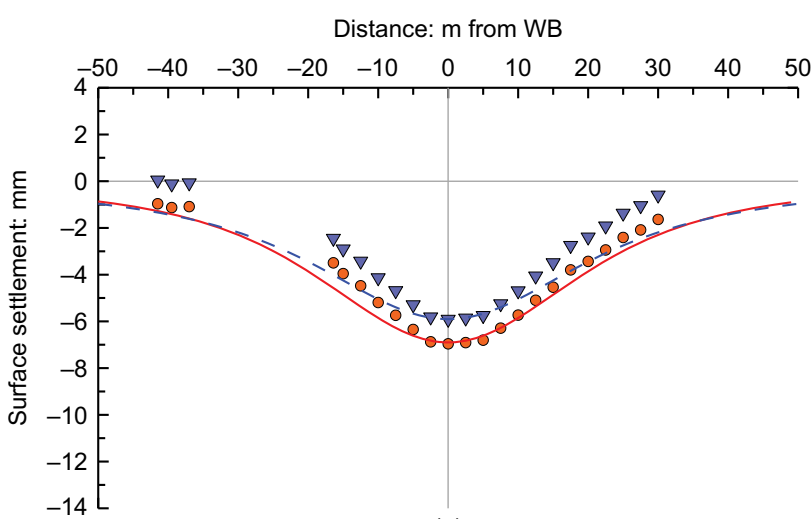

(a)

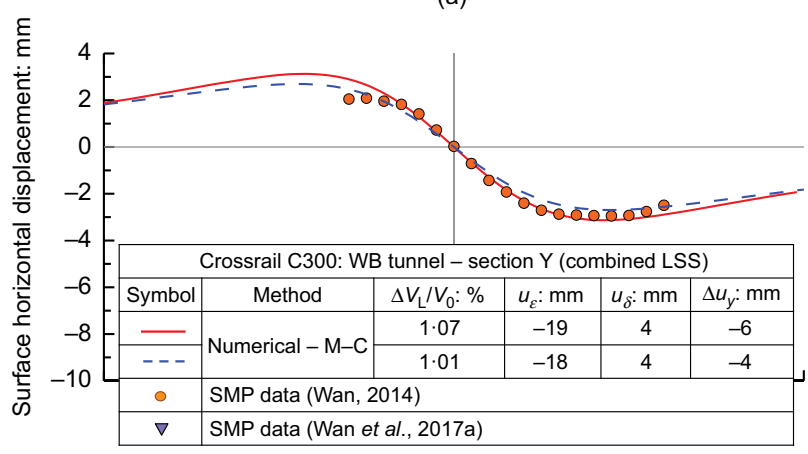

(b)

Fig. 22. Section Y WB surface: (a) vertical and (b) horizontal displacements compared against numerical solutions (dashed lines based on data from Wan (2014); solid lines - data from Wan et al. (2017a)) (M-C, Mohr-Coulomb; SMP, surface monitoring point)
Authors' reply

The authors are grateful for the interest shown by the discussers and their comments and contributions. The authors address these in the following paragraphs in the order they are presented in the discussion.

First, in response to the discussers' observations concerning the TBM operational variables (face pressure and tail-skin grout pressure), the authors have presented these for both sections $\mathrm{X}$ and $\mathrm{Y}$ as well as eight of the other sections referred to by the discussers (Fig. 23 in Wan et al. (2017a) where the sections are numbered 1 to 8 rather than $\mathrm{A}$ to $\mathrm{H}$ as given in the paper by Ieronymaki et al. (2016)). The TBM data presented by Ieronymaki et al. (2016) do not include sections $\mathrm{X}$ and $\mathrm{Y}$, as they start from a chainage point shortly after the more easterly section X. In the authors' view, from what they observe in the profiles presented by Wan et al. (2017a), there are negligible differences between these two sections (final sentence on p. 429), although it is acknowledged in the authors' reply here that the tail-skin grouting pressure was indeed about $10 \mathrm{kPa}$ lower at section $\mathrm{X}$ for the WB tunnel construction, which might have had an additional minor influence (the grout pressure at that location was about $100 \mathrm{kPa}$ )

Second, with regard to the datum used, this is clearly discussed in Wan et al. (2017a); p. 430. When planning the monitoring array the authors intentionally included a deep extensometer anchor at $50 \mathrm{~m}$ depth in HP21 (see Wan et al., 2017b; Fig. 2a), thinking that this should be a stable datum. This was used in the initial interpretation of the data by Wan (2014). It was then realised from both the numerical analysis and processing of the monitoring data that the ground at this depth in the vicinity of the WB tunnel heaved in response to

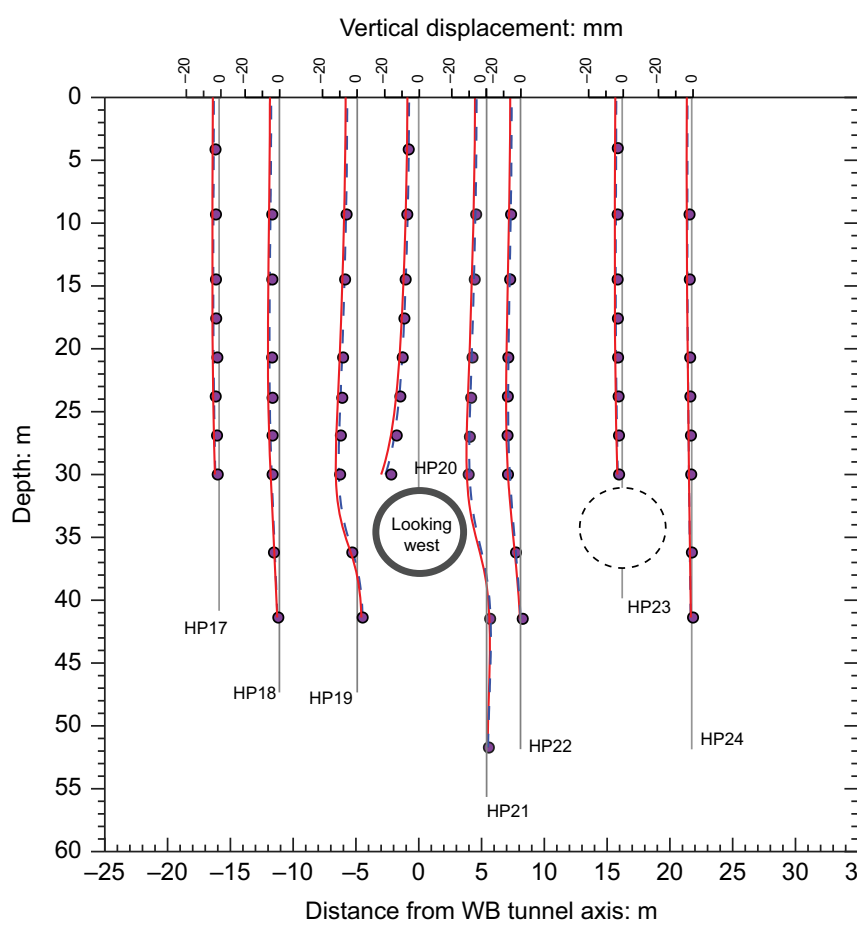

(a)

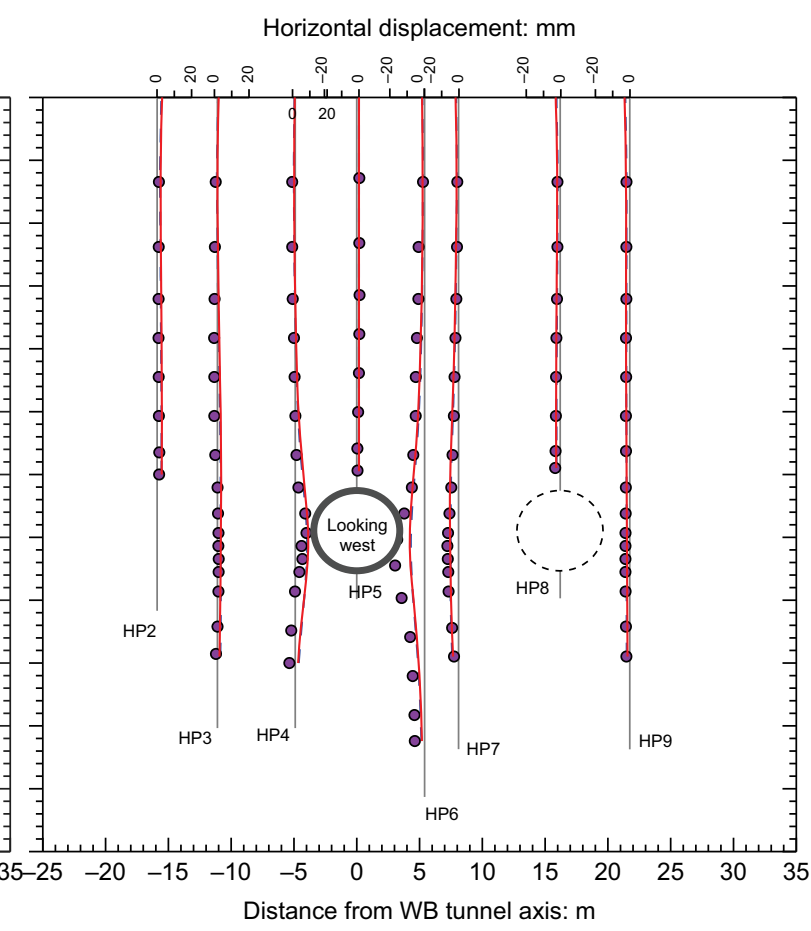

(b)

\begin{tabular}{|c|c|c|c|c|c|}
\hline \multicolumn{6}{|c|}{ Crossrail C300: WB tunnel - section Y (combined LSS) } \\
\hline Symbol & Method & $\Delta V_{L} / V_{0}: \%$ & $u_{\varepsilon}: \mathrm{mm}$ & $u_{\delta}: \mathrm{mm}$ & $\Delta u_{y}: \mathrm{mm}$ \\
\hline - & \multirow{2}{*}{ Numerical - M-C } & $1 \cdot 07$ & -19 & 4 & -6 \\
\hline--- & & $1 \cdot 01$ & -18 & 4 & -4 \\
\hline - & \multicolumn{5}{|l|}{ Inclinom } \\
\hline
\end{tabular}

Fig. 23. Section Y WB subsurface: (a) vertical and (b) horizontal displacements (only data from Wan et al. (2017a) are shown) compared against numerical solutions (dashed lines - based on data from Wan (2014); solid lines - data from Wan et al. (2017a)) 
the first tunnel passing above the datum (as stated in Wan (2014), p. 111, and Wan et al. (2017a), p. 430). Therefore the data were reanalysed using the $40 \mathrm{~m}$ deep anchor in HP24 as a fixed datum (located below the invert level of the WB tunnel and about $20 \mathrm{~m}$ offset - see again Fig. 2a of Wan et al. (2017b)). This is stated in Wan et al. (2017a) and also Avgerinos et al. (2018), along with the observation that using the $50 \mathrm{~m}$ deep datum would result in 'apparently greater vertical displacements', which is evident from the data presented by the discussers in Fig. 22(a).

Third, with respect to the discussers' numerical method used to generate the results that they present in Figs 22 and 23, there are significant differences compared with the approach used by the authors. These are discussed further below.

In the discussers' numerical approach they assume that, after construction, the deformed shape of the tunnel can be approximated by a combination of a uniform convergence (i.e. deforms in a circular mode with the centre fixed), an elliptical mode (i.e. elongates in the horizontal direction with the centre fixed) and vertical (i.e. downward) translation. These three modes of deformation are defined by the 'parameters' $\mu_{\varepsilon}, \mu_{\delta}$ and $\mu_{y}$, respectively. They then define a realistic range for these parameters and perform a large number of numerical analyses, each of which is for a particular combination of these parameters within the selected range. When doing these analyses the finite-element mesh is designed such that there are nodes at the location where field measurements of surface and subsurface displacements are available. The predicted displacements at these nodes are then stored for each analysis, and therefore each combination of $\mu_{\varepsilon}, \mu_{\delta}$ and $\mu_{y}$ is held within a database. This database is then searched to find the analysis that gives the best overall match with the field observations using a least-squares approach. This gives the optimum values of $\mu_{\varepsilon}$, $\mu_{\delta}$ and $\mu_{y}$. The authors provide the following comments on the discussers' numerical approach.

(a) This approach is essentially a back-analysis as it requires a significant amount of field data related to soil movements. For example, the discussers cite 220 deformation component measurements in their discussion. It is therefore perhaps not surprising that the discussers obtain a good fit with the field data, as these same data have been used in the optimisation process described above.

(b) It is difficult (probably impossible) to measure $\mu_{\varepsilon}, \mu_{\delta}$ and $\mu_{y}$ in the field and therefore to validate the numerical values directly.

(c) As the measured field data provide soil displacements in the short term, this numerical approach has assumed the London Clay deforms in an undrained manner. The method does not provide information on long-term or transient movements.

(d) At present this approach can only deal with a single tunnel.

(e) As the tunnel lining is not modelled, no information is provided on the forces within it.

( $f$ ) In this numerical approach displacements are applied at the nodes representing the tunnel boundary.

Consequently reactions (i.e. forces) act at these nodes after the displacements have been applied. The discussers' numerical approach stops here and consequently these reactions are implicitly contained within the solution but are not dealt with further. In a real tunnel scenario these forces must be balanced and, as only the tunnel lining exists after construction, these forces must be transferred to the lining. The authors have performed analyses in which they have applied a displaced shape to the tunnel boundary, as in the discussers' approach, but have then constructed a lining and then released the reactions so that the forces are transferred to the lining-soil system. This induces forces in the lining but also, more importantly, further displacements in the soil. As the field measurements correspond to the case where the tunnel lining is in place, it is the final movements from the numerical analyses (with lining in place) that should be compared with the field data. The error involved in the discussers' approach will then depend on the soil movements that occur when the reaction forces are transferred to the lining and this will depend on the nature of the lining (i.e. segmental, shotcrete) and its stiffness, as well as the stiffness of the soil.

In the authors' numerical approach, tunnel construction involves the excavation of the soil elements within the tunnel boundary over several increments of the analysis. The procedure is first to calculate the nodal forces that these elements apply to the tunnel boundary and then to simultaneously apply exactly equivalent forces as these soil elements are removed from the finite-element mesh. As there is no disturbance to equilibrium there are no displacements or stress changes during this procedure. The second stage involves removal of these forces in small steps over several increments of the analysis. After each increment, the predicted displacements at the tunnel boundary are used to calculate the amount of soil moving into the tunnel and hence the volume loss. When this volume loss approaches the target value, the tunnel lining is constructed and the remaining increments, associated with the removal of the forces, are with the lining in place. This results in forces being transmitted to the lining and no fictitious reaction forces existing at the end of the analysis. The displacements of the tunnel boundary at the end of this process are then used to calculate the volume loss and this is compared to the target value. If there is a significant discrepancy between these values then the analysis is repeated, removing the forces over more increments and/or constructing the lining at a different increment. The following comments are provided.

(a) As field data are not part of the numerical procedure the authors' approach can be applied prior to tunnel construction. However, a target value of the volume loss is required. This could be based on past experience or related to the design value.

(b) The method can be part of coupled analyses in which transient and long-term behaviour can be analysed.

(c) It can be incorporated in an analysis involving more than one tunnel.

(d) It can account for the nature and shape of the tunnel lining (i.e. shotcrete, segmental).

(e) The analyses presented in the original paper under discussion involved points $(b)-(d)$ above, with the volume loss target set to the value measured in the field.

Finally, it is noted that both the authors' and discussers' approaches involve a 2D plane strain approximation of the tunnel construction process, whereas in reality this is a complex three-dimensional problem.

\section{REFERENCES}

Avgerinos, V., Potts, D. M., Standing, J. R. \& Wan, M. S. P. (2018). Predicting tunnelling-induced ground movements and interpreting field measurements using numerical analysis: Crossrail case study at Hyde Park. Géotechnique 68, No. 1, 31-49, https://doi.org/10.1680/jgeot.16.P.219. 
Ieronymaki, E. S. (2015). Prediction and interpretation of ground movements due to tunneling in stiff clay and impacts on adjacent structures. PhD thesis, Massachusetts Institute of Technology, Cambridge, MA, USA.

Ieronymaki, E. S., Whittle, A. J. \& Sureda, D. S. (2016). Interpretation of free-field ground movements caused by mechanized tunnel construction. J. Geotech. Geoenviron. Engng 143, No. 4, 04016114.

Ieronymaki, E. S., Whittle, A. J. \& Einstein, H. H. (2018). Comparative study of the effects of three tunneling methods on ground movements in stiff clay. Tunnelling Underground Space Technol. 74, 167-177.

Pinto, F. \& Whittle, A. J. (2014). Ground movements due to shallow tunnels in soft ground: 1. Analytical solutions. ASCE J. Geotech. Geoenviron. Engng 140, No. 4, 0401.3040 .

Pinto, F., Zymnis, D. \& Whittle, A. J. (2014). Ground movements due to shallow tunnels in soft ground: 2. Evaluation of analytical solutions. ASCE J. Geotech. Geoenviron. Engng 140, No. 4, 0401.3041.

Wan, M. S. P. (2014). Field monitoring of ground response to EPBM tunneling close to existing tunnels in London Clay. PhD thesis, Imperial College London, London, UK.

Wan, M. S. P., Standing, J. R., Potts, D. M. \& Burland, J. B. (2017a). Measured short-term ground surface response to EPBM tunnelling in London Clay. Géotechnique 67, No. 5, 420-445, https://doi.org/10.1680/jgeot.16.P.099.

Wan, M. S. P., Standing, J. R., Potts, D. M. \& Burland, J. B. (2017b). Measured short-term subsurface ground displacements from EPBM tunnelling in London Clay. Géotechnique 67, No. 9, 748-779, https://doi.org/10.1680/jgeot.SIP17.P.148.

Whittle, A. J. \& Sagaseta, C. (2003). Analyzing the effects of gaining and losing ground. In Soil behavior and soft ground construction (eds J. T. Germaine, T. C. Sheahan and R. V. Whitman), vol. 119, pp. 255-291. Reston, VA, USA: American Society of Civil Engineers (ASCE). 